

\title{
Keywords
}

acute pancreatitis; acute recurrent pancreatitis; chronic pancreatitis; pancreatic insufficiency; diabetes

Pediatric pancreatic diseases are increasingly recognized in childhood, possibly due to increased awareness among physicians ${ }^{1}$. Acute pancreatitis (AP) is estimated to occur at an incidence approaching that of adults. Although AP resolves without complications in most children, a subset continues to have recurrent attacks of pancreatitis (acute recurrent pancreatitis or ARP) and some progress to chronic pancreatitis (CP). In contrast to the adult population, most children with ARP or CP have genetic mutations; environmental risk

Corresponding Author: Designate one author to serve as correspondent. This author will receive article proof to correct and return. Aliye Uc.

Aliye Uc, M.D., BT1120-C JPP Stead Family Department of Pediatrics, The University of Iowa Carver College of Medicine, 200 Hawkins Drive, Iowa City, IA 52242; Tel: (319) 384-6032; Fax:(319) 353-8967; aliye-uc @uiowa.edu

Douglas S. Fishman, M.D., Texas Children’s Hospital, 6701 Fannin Street, Clinical Care Tower, 1010. Houston, Texas 77030; Tel (832) 822-1050; dsfishma@bcm.edu

Publisher's Disclaimer: This is a PDF file of an unedited manuscript that has been accepted for publication. As a service to our customers we are providing this early version of the manuscript. The manuscript will undergo copyediting, typesetting, and review of the resulting proof before it is published in its final citable form. Please note that during the production process errors may be discovered which could affect the content, and all legal disclaimers that apply to the journal pertain.

Disclosure statement

Disclose any relationship with a commercial company that has a direct financial interest in subject matter or materials discussed in article or with a company making a competing product. If nothing to disclose, please state "The Authors have nothing to disclose." None (AU, DF) 
factors are rare. Disease burden is significant in CP. Cystic fibrosis (CF) is the most common cause of exocrine pancreatic insufficiency (EPI) in childhood, followed by ShwachmanDiamond syndrome (SDS) and CP. Long-term effects of pancreatic diseases in children include possible nutritional deficiencies, pancreatogenic diabetes and potentially pancreatic cancer later in life.

\section{ACUTE PANCREATITIS}

\section{Risk Factors/Etiologies}

Recent studies estimate the incidence of acute pancreatitis (AP) at 3.6 and 13.2 cases per 100,000 children per year ${ }^{1}$, which is similar to incidences reported in adults ${ }^{2}$. Table 1 lists etiologies of acute pancreatitis in children.

There are unique differences between risk factors of adult and pediatric $\mathrm{AP}^{3-17}$. In adults, alcohol use and gallstones account for the majority of cases, while etiologies in children are broad and variable. Biliary/obstructive factors, systemic illness and medications are commonly identified in childhood AP; $15-30 \%$ cases are idiopathic. AP triggered by genetic mutations, metabolic factors, trauma or alcohol is uncommon in children. In infants and toddlers, systemic illness is the leading cause ${ }^{3}$.

\section{Pathophysiology}

Pancreatitis may occur in the setting of an inciting factor (e.g. medication, obstruction, genetic mutation) which triggers a cascade of events. There are several competing mechanisms of pancreatic inflammation including the traditional trypsin-dependent theory (activation of the enzymes leading to destruction of pancreas) ${ }^{18}$; inflammatory pathways (supported by animal models lacking trypsinogen and still developing inflammation) ${ }^{19}$; and finally endoplasmic reticulum stress (independent of trypsin activation) ${ }^{20}$. Models that mimic human disease are needed to better dissect the mechanisms of pancreatic inflammation.

\section{Clinical manifestations}

The most common symptoms of AP are abdominal pain and vomiting. Young children may present with vague symptoms and/or irritability, thus diagnosis in this age group requires a high degree of suspicion ${ }^{3}$. Signs and symptoms of cholangitis may be present in gallstone pancreatitis, but mild jaundice and liver enzyme elevations may occur in non-biliary pancreatitis due to significant inflammatory changes in the distal bile duct as it traverses through the head of the pancreas.

\section{Diagnosis}

Acute pancreatitis is a clinical diagnosis based on a combination of history, physical examination, laboratory testing and imaging findings as listed in Table $2^{21}$.

Laboratory findings-Amylase and lipase are the most commonly used biochemical markers of pancreatic inflammation. Both amylase and lipase elevations are not specific for AP, but lipase appears to be a more sensitive marker for pancreatitis. In the absence of a 
known etiology or family history, liver indices (aminotransferases, conjugated and unconjugated bilirubin and GGT) along with fasting glucose, triglycerides, calcium are recommended laboratory studies for the first episode of AP.

Imaging findings-Imaging maybe done to confirm AP and/or its complications, assessing pancreatic parenchyma and the surrounding organs and vasculature. Imaging may include transabdominal US (TUS), Contrast Enhanced CT (CECT), Magnetic Resonance Imaging (MRI) of the abdomen including MRCP (Magnetic Resonance Cholangiopancreatography) and endoscopic ultrasound (EUS).

In children, TUS is the first-line study based on its diagnostic yield and safety profile ${ }^{22}$. In AP, the pancreas may appear normal on TUS, or difficult to visualize due to intestinal air; echogenicity may be variable. The advantages of TUS are its lower cost compared to other modalities, no need for sedation and no ionizing radiation. TUS is useful for identifying biliary tract disease, including gallstones, choledochal cyst, common bile duct stones or biliary tract dilation. TUS can also identify acute fluid collections, peripancreatic inflammation and masses. The use of Doppler may delineate splenic vein thrombosis or other vascular changes.

Cross sectional imaging such as CECT and MRI have a limited role in $\mathrm{AP}^{23}$. CECT can provide high resolution images and assess pancreatic parenchyma, peripancreatic tissues and nearby vessels and organs, but it is not effective in assessing non-dilated pancreatic ducts. CECT is routine in adult patients with pancreatitis, but due to risks of ionizing radiation, it is not routinely performed in pediatrics ${ }^{24,25}$. Of note, recent adult guidelines recommend deferring CECT and/or MRI for the first 48-72 hours unless the diagnosis is in question or in those who fail to demonstrate clinical improvement ${ }^{26}$.

MRI/MRCP are not typically ordered for AP. The two most common scenarios in which MRI, specifically MRCP is useful in children are 1) young children with pancreatitis to identify significant pancreatic anomalies ${ }^{27}$ and 2) patients with gallstone pancreatitis with inconsistent laboratory and ultrasound findings ${ }^{28}$. The most significant risk-benefit assessment for pediatric patients in using MRI is the possible need for sedation/anesthesia for completion of the study. MRCP does not require contrast, but risks of gadolinium and related MR-contrast agents should be used with caution in those with renal impairment or allergy to the agents.

\section{Complications}

In general, AP has a mild course in childhood and resolves without significant complications. When complications occur, they can be local or systemic. Local complications include acute peripancreatic fluid collection, pancreatic pseudocyst (Figure 1), acute necrotic collection and walled-off necrosis (Table 3). They should be suspected when there is persistence or recurrence of abdominal pain, secondary increases in pancreatic enzymes, organ dysfunction or signs and symptoms of sepsis, such as fever and leukocytosis. ${ }^{29}$ Other local complications are poor gastric motility, splenic and portal vein thrombosis, and colonic necrosis. Systemic complications include organ failure, most 
commonly respiratory, cardiovascular and renal. The 2012 Atlanta classification grades AP severity as mild, moderately severe or severe (Figure 2) (Table 4$)^{29}$.

The scoring systems to assess the severity of pancreatitis in adults (Ranson, Glasgow, modified Glasgow, Bedside Index of Severity in Acute Pancreatitis (BISAP) and APACHE II) cannot be easily applicable to children. The DeBanto scoring system was the first system to assess severity in a pediatric cohor ${ }^{30}$. A more recent scoring system proposes using lipase, albumin and WBC obtained within $24 \mathrm{~h}$ of admission to predict severity ${ }^{31}$.

Developing a severity score in pediatrics is challenging, as severe complications are uncommon and death is very rare.

\section{Management (Figure 3)}

The most important component in the management of AP is fluid therapy. Fluid resuscitation is thought to maintain pancreatic microcirculation and prevent major complications, such as necrosis and organ failure. Lactated ringer has been shown to reduce systemic inflammation and thus prevent complications in adults with AP compared to saline. ${ }^{32}$ Early and aggressive fluid resuscitation in children with normal saline and 5\% Dextrose is safe and well-tolerated, but has not been compared to other fluids. ${ }^{33}$ The rates of IV fluid in pediatric AP have also not been assessed. One study showed that a combination of early enteral nutrition ( $<48$ hours) and aggressive fluid management $(>1.5-2 \mathrm{x}$ maintenance within the first 24 hours) decreased length of stay and complications. ${ }^{33}$

In both children and adults, the initial nutritional management of AP remains controversial. The American College of Gastroenterology recommends oral feedings for mild AP when patients symptoms are significantly improved and feeding with a low-fat solid diet appears as safe as a clear liquid diet ${ }^{26}$. Overall, it is agreed that children with mild to moderate disease require minimal to no additional nutritional support, enteral nutrition is preferred over parenteral nutrition and nutritional support should begin within 48-72 hours ${ }^{34}$. For patients with severe AP, enteral nutrition is recommended to prevent infectious complications, decrease inflammatory response, reduce mortality and improve outcome. Early enteral nutrition appears to be safe in children ${ }^{33}$, but more studies are needed.

Pain is managed with opioids, specifically IV morphine initially. Despite earlier concerns about Sphincter of Oddi dysregulation with morphine, there is no clinical evidence to support this theory ${ }^{35}$. Once tolerating oral feedings, patients may transition to oral acetaminophen or nonsteroidal anti-inflammatory drugs (NSAID) alone or combined with an opioid.

Endoscopic procedures for AP are limited to EUS and ERCP. ERCP is recommended in gallstone pancreatitis with choledocholithiasis, cholangitis, or in those with concern for biliary obstruction ${ }^{36,37}$. In adults with gallstone pancreatitis, EUS and MRCP are preferred in those without jaundice or cholangitis, however this has not been formally studied in children. EUS drainage via endoscopic cystgastrostomy has become the standard modality for drainage of pancreatic pseudocysts and pancreatic necrosis in adults and children ${ }^{38}$. Surgery for AP is infrequently performed, and typically for pseudocyst drainage, 
debridement of necrosis or cholecystectomy. Recent studies show that early cholecystectomy after mild biliary pancreatitis is safe in children and reduces readmissions. ${ }^{39-41}$

\section{ACUTE RECURRENT AND CHRONIC PANCREATITIS}

\section{Risk Factors/Etiologies}

A subset of children with AP (15-35\%) develop recurrent episodes of AP and may progress to $\mathrm{CP}^{21}$. Definitions of ARP and CP are listed in Table 2. Because ARP and CP are rare, large cohorts and multicenter studies are needed to characterize these diseases ${ }^{42}$. Conditions that predispose children to ARP then $\mathrm{CP}$ are listed in Table 5; genetic risks are the most common. In the large multicenter INSPPIRE (INternational Study Group of Pediatric Pancreatitis: In search for a cuRE) cohort, $\sim 50 \%$ of children with ARP and $\sim 75 \%$ of $\mathrm{CP}$ had genetic mutations in the cationic trypsinogen (PRSS1), cystic fibrosis transmembrane generator (CFTR), serine protease inhibitor Kazal type I (SPINK1), chymotrypsin-C (CTRC); PRSS1, SPINK1 mutations were more common in $\mathrm{CP}^{43}$, 44 . Moreover, carboxypeptidase 1 (CPA1) mutations were associated with early-onset $\mathrm{CP}^{45}$. The genetic variants in the carboxylesterlipase (CEL) and CEL-Hybrid ${ }^{46,47}$ increase the risk for CP in adults.

Environmental risk factors (i.e. medications, alcohol, smoking, chronic renal failure, hypercalcemia) are uncommon in pediatric ARP or CP $(<10 \% \%)^{43}$. It is not known whether obstructive factors and specifically pancreas divisum are sufficient to cause ARP or CP in children. Autoimmune pancreatitis (AIP) is rare in the pediatric population.

\section{Clinical manifestations}

Children with ARP suffer from recurrent attacks of AP, but are in normal health in between episodes. Children with CP suffer from pain that ranges from mild to severe, episodic to constant $^{43}$. Need for pain medications, disease burden (emergency department visits, hospitalizations, missed school days, medical, endoscopic and surgical interventions) and health care cost were much higher in CP compared to ARP in the INSPPIRE cohort ${ }^{44,48}$.

Over time, children with CP can develop exocrine pancreatic insufficiency (EPI) and pancreatogenic diabetes mellitus (T3cDM). Diabetes occurs in $~ 5 \%$ of patients with hereditary pancreatitis by 10 years after the onset of symptoms, and $18 \%$ by 20 years ${ }^{49}$. Although the mechanism of this diabetes is unknown, partial or complete insulin deficiency is observed. In the INSPPIRE cohort, $1 \%$ of children already had diabetes at the time of enrollment ${ }^{43}$.

\section{Diagnosis}

The guidelines for causal evaluation of ARP and $\mathrm{CP}$ was recently published by the INSPPIRE group ${ }^{50}$. The diagnosis of ARP and CP requires a careful past medical and family history, inquiry of past pancreatitis attacks, abdominal pain, hospitalizations, emergency room visits and possible complications of AP. Family history for AP, ARP and $\mathrm{CP}$, pancreatic cancer and diabetes have to be explored (Table 6). Testing for autoimmune 
pancreatitis may not be straightforward as most children have type 2 disease and typically normal serum IgG4.

Imaging studies play an important role in the work-up to evaluate obstructive risk factors and explore the presence of AP/CP (Figure 4 and 5). TUS is the first imaging test of choice, but it may not clearly delineate the pancreas anatomy. CT can detect advanced changes in $\mathrm{CP}$, including calcifications, pancreas atrophy, fat replacement, but it has poor sensitivity to identify ductal abnormalities and subtle parenchymal changes. MRI/MRCP can reliably detect pancreas atrophy, ductal dilatations, small filling defects, strictures, irregularities of the main pancreatic duct, and irregularity of side branches ${ }^{51}$ and it has become the diagnostic imaging method of choice in children ${ }^{52}$. Secretin may increase the detectability of the normally small pancreatic ducts on $\mathrm{MRCP}^{53}$. EUS can assist with the diagnosis in ARP and CP, specifically in microlithiasis and pancreatic anomalies (e.g. pancreas divisum). However, specific criteria (Rosemont and Cambridge) available for EUS descriptions of CP in adults ${ }^{54}$ have not been validated in children. Finally, ERCP should be reserved for therapeutic purposes.

\section{Management}

Medical-In the INSPPIRE cohort, $\sim 80 \%$ of children with ARP or CP reported pain within the previous year that was of variable frequency and severity; one third of children with $\mathrm{CP}$ were using narcotic analgesics ${ }^{43}, 44$. Pediatric experience is limited for the treatment of pain in ARP/CP. Due to increased greater understanding about pain mechanisms in pancreatitis as well as the significant burden of addiction, there has been a significant emphasis on opioidfree therapies, such as GABA-analogues (egg. gabapentin and pregabalin) ${ }^{55}$. Pediatric studies are needed to study the efficacy and safety of these medications in children. There is no data to support the benefit of anti-oxidant preparations or pancreatic enzyme supplementation in pediatric ARP/CP. There is also limited data on calorie/energy requirement, nutritional needs, macro and micronutrient deficiencies in children with ARP or $\mathrm{CP}$.

Endoscopic-ERCP is reserved as therapeutic modality for ARP or CP. ERCP can also provide short-term symptom relief in pediatric patients ${ }^{56-58}$. Sphincterotomy, stent placement and stone removal are the most common therapies. Overall, ERCP is safe in children, but risk of anesthesia/sedation, post-ERCP pancreatitis and ionizing radiation should be considered. Extracorporeal shock wave lithotripsy has been used in pediatric patients with large pancreatic duct stones ${ }^{57}$, but it is not available in most centers.

Surgical-Surgery for $\mathrm{CP}$ involves drainage procedures and partial or total resections. Surgical drainage procedures typically require the presence of a dilated pancreatic duct $>5$ $6 \mathrm{~mm}$. In the majority of cases, a Puestow-type procedure (longitudinal pancreatojejunostomy that involves opening the pancreatic duct throughout the body and tail of the gland) is used. Drainage procedures are discouraged if the patient will undergo total pancreatectomy and islet auto-transplantation (TPIAT) in the future, since they adversely affect the islet yield from the pancreas. $.59,60$ 
TPIAT is increasingly performed in specialized centers for pediatric ARP/CP intractable to other therapies. Within a year of this operation, $50-80 \%$ of patients became narcotic independent on follow-up ${ }^{60-65}$. The pain improvement was largely sustained at 10-year follow-up, whereby $10-20 \%$ of patients continued to take narcotics ${ }^{61,64}$. Similarly, insulin independence was also sustained over the 10-year follow-up in the majority of children $(\sim 40 \%)^{61}$. Both children and adults demonstrated significant improvement in physical and mental health after TPIAT ${ }^{60,63,64,66}$. Prospective studies are needed to study the long term effects of TPIAT in children.

\section{EXOCRINE PANCREATIC INSUFFICIENCY (EPI)}

The pancreas is a resilient organ. Clinically significant EPI causing steatorrhea develops only after a large portion of pancreatic acini $(>90 \%)$ is permanently damaged. The causes of EPI in childhood are listed in Table 7.

\section{Cystic Fibrosis}

Cystic fibrosis (CF) is by far the most common cause of EPI in childhood. Caused by mutations in the Cystic Fibrosis Transmembrane Regulator Protein (CFTR), pancreas involvement begins in utero in children with CF and progresses into childhood. CFTR is typically expressed in pancreatic duct epithelia and controls anion secretion into the lumen. Loss of CFTR function impairs fluid and anion secretion which then leads to acidic luminal contents, plugging of ducts and eventual destruction of the pancreas. The type of $C F T R$ mutations greatly influences the degree of exocrine pancreatic involvement; $85 \%$ are pancreatic insufficient and depend on pancreatic enzymes to maintain adequate growth and nutrition, while $15 \%$ are pancreatic sufficient. Pancreatic status is directly linked to genotype ${ }^{30}$. Patients with homozygous or compound heterozygous mutations that belong to class I-III or VI mutations that severely alter CFTR function suffer from EPI, versus patients with class IV or V mutations who are usually pancreatic sufficient ${ }^{67,68}$. Pancreas sufficient patients are prone to recurrent attacks of pancreatitis and may eventually become pancreatic insufficient ${ }^{69}$. In a rare instance, pancreatitis may be the first manifestation of CF. Ooi et al estimated the risk of EPI and pancreatitis for the most common CF-causing mutations by using Pancreatic Insufficiency Prevalence (PIP) score. The score is higher for the severe mutations and lower for mild mutations. ${ }^{70}$

\section{Shwachman-Diamond syndrome (SDS)}

SDS is a rare autosomal recessive disorder characterized by congenital anomalies, EPI, bone marrow defects and short stature. ${ }^{71}$ Ninety percent of children with SDS have mutations in the Shwachman-Bodian-Diamond Syndrome (SBDS) gene located on chromosome 7q11. In contrast to CF, pancreatic ductal function is normal in SDS.

The presentation of SDS may be variable. Neutropenia is the most common hematologic abnormality at presentation ( $80 \%)$, but it may be intermittent or develop over time ${ }^{71}$. Twothird of patients present with failure to thrive, only $50 \%$ describe diarrhea. Pancreatic lipomatosis is not universal, low fecal elastase levels may be present in $\sim 80 \%$ of patients at presentation. Skeletal abnormalities are the most common congenital abnormality, reported 
in one third of patients. ${ }^{72} \mathrm{~A}$ wide variety of congenital anomalies involving the cardiac, gastrointestinal, renal, neurologic, urologic, and other systems have been reported. Over time, patients are prone to developing myelodysplasia and leukemia. Poor growth does not usually improve despite adequate pancreatic replacement therapy. EPI is often transient, and steatorrhea may spontaneously improve over time. Recurrent infections are common and a frequent cause of death.

Diagnosis of SDS is often made clinically by documenting the presence of EPI and hematologic abnormalities, excluding other causes of EPI and bone marrow failure. Consensus guidelines have been developed to facilitate early diagnosis and therapy ${ }^{73}$.

\section{Chronic Pancreatitis (CP)}

Exocrine pancreatic insufficiency develops in 50-80\% of adults after a diagnosis of 5.6 to 13.1 years $^{74,75}$. The exact prevalence of EPI in pediatric CP is unknown, but $34 \%$ of children with $\mathrm{CP}$ in the INSPPIRE cohort were exocrine pancreatic insufficient at the time of enrollment ${ }^{43}$. Typically, the diagnosis of CP is made prior to the diagnosis of EPI. Interestingly, in a Norwegian family, EPI was diagnosed after the diagnosis of maturityonset diabetes of the young (MODY) and discovery of $C E L$ mutations. $^{76}$

\section{Johanson-Blizzard syndrome (JBS)}

This rare autosomal recessive disorder is caused by mutations in ubiquitin ligase (UBR1) gene that leads to destruction of pancreatic acini in utero ${ }^{77}$. Pancreatic ductal function is unaffected. Patients usually present with EPI, multiple congenital anomalies, hypothyroidism and developmental delay. Diabetes may develop over time. In contrast to SDS, children with Johanson-Blizzard syndrome do not have bone marrow and skeletal abnormalities. Milder JBS phenotypes have been described, thus the absence of multiple congenital anomalies or mental retardation does not rule out this syndrome. ${ }^{78,79}$

\section{Pearson Syndrome}

This is a rare multisystem disorder caused by defects in the oxidative phosphorylation due to sporadic mutations in the mitochondrial DNA ${ }^{80}$. Patients typically present in infancy with severe, transfusion-dependent, hypoplastic macrocytic anemia; variable degree of neutropenia and thrombocytopenia; and normal or reduced bone marrow cellularity with vacuolated precursors. Other features are exocrine and endocrine pancreas dysfunction, hyperlipidemia, liver steatosis, proximal renal tubular insufficiency, metabolic acidosis, failure to thrive. Pearson Syndrome is distinguished from SDS by the presence of sideroblastic anemia, bone marrow changes, pancreatic fibrosis rather than lipomatosis, and absence of bone lesions. Diagnosis is confirmed by Southern blot analysis that detects mtDNA rearrangements. There is no specific treatment available and patients usually succumb to death in infancy or early childhood due to metabolic disorders and/or infections.

\section{Other causes}

Jeune syndrome, pancreatic aplasia, pancreatic hypoplasia, isolated pancreatic enzyme deficiencies (pancreatic lipase deficiency or PNLIP) are rare causes of EPI in childhood. 
Clinical manifestations-EPI presents primarily as fat malabsorption defined by a fecal fat greater than $7 \%$ of oral fat intake in a 3-5 day fat balance studies. Fat malabsorption, steatorrhea (bulky, foul-smelling stools) and malnutrition are the hallmarks of EPI. Patients suffer from poor weight gain or weight loss, diarrhea, steatorrhea, bloating and flatulence. Fat malabsorption can lead to deficiencies of fat soluble vitamins A, D, E, and K.

Diagnosis-Tests for EPI are classified as direct and indirect tests (Table 8). The direct pancreatic function tests (PFTs) involve the stimulation of pancreas with pancreatic secretagogues followed by collection of duodenal fluid and analysis of its contents for pancreatic enzymes (acinar cell function), and/or fluid volume and electrolytes (ductal cell function). The direct pancreatic function tests are more sensitive and specific than indirect tests, but they are invasive and difficult to perform. Indirect tests are widely available and easier to perform but have low sensitivity and specificity. Although the indirect tests are useful to diagnose EPI, they cannot accurately measure the pancreatic acinar cell reserve and ductal cell function.

\section{1-Direct Tests}

- $\quad$ Secretin-stimulated MRI/MRCP: Exocrine pancreas function is studied by changes in pancreatic duct caliber, anteroposterior diameter of the pancreas, signal intensity ratio between pancreas and spleen on T1-weighted and arterialvenous enhancement ratios and duodenal filling before and after secretin. The study is highly subjective, operator dependent, lacks sensitivity and specificity ${ }^{81}$. This test has not yet been validated in children.

- $\quad$ Dreiling tube method: In this test, pancreatic fluid is collected as it is secreted into the duodenum and measured for volume, pancreatic enzymes and electrolytes before and after stimulation with cholecystokinin and/or secretin ${ }^{82}$. Although it is considered "gold standard" to quantify the exocrine pancreatic function, the invasive and complex nature of the test (placement of nasoduodenal catheter, IV cannulation, sedation, and radiation exposure) limits its routine clinical use.

- $\quad$ Endocsopic pancreatic function test (ePFT): The collection of the duodenal fluid via the endoscope ${ }^{83}$ is becoming increasingly popular in the pediatric age group. In this tests, duodenal fluid is aspirated during an upper gastrointestinal endoscopy procedure before and after stimulation with a pancreatic secretagogue. ePFT leads to prolonged sedation or anesthesia and samples are likely to be diluted with gastric fluid. There is a lack of standardization between protocols among the centers about which secretagogues to use and type and frequency of samples to collect. In one study, ePFT underestimated the pancreatic secretory capacity and led to erroneous classification of patients as pancreatic insufficient ${ }^{82}$.

\section{1-Indirect Tests}

- $\quad$ 72-hour fecal fat test. Steatorrhea can be measured by a 72-hour stool collection and calculation of coefficient of fat absorption [CFA: (grams of fat ingested- 
grams of fat excreted)/(grams of fat ingested) x100]. In children younger than 6 months of age, a fecal fat greater than $15 \%$ of fat intake is considered abnormal; this value is $7 \%$ for children over 6 months of age. It is not a specific test for EPI as it can be abnormal in other diseases causing fat malabsorption. The test is not easy to perform, stool samples may be missed, dietary documentation may be incomplete.

- $\quad$ Fecal elastase-1 (FE1). This widely available ELISA-based stool test is the preferred method to diagnose $\mathrm{EPI}^{84}$. A value of less than $100 \mu \mathrm{g} / \mathrm{g}$ is considered diagnostic. The test is only useful to detect severe EPI. Results may be falsely low when the stool is diluted in cases of diarrhea.

- $\quad{ }^{13} \mathrm{C}$-mixed triglyceride breath test: This test relies on the hydrolysis of ingested triglycerides by pancreatic lipase and measurement of ${ }^{13} \mathrm{CO}_{2}$ released to breath. Numerous factors such as rate of gastric emptying, degree of solubilization by bile acids, mucosal absorption, endogenous $\mathrm{CO}_{2}$ production, and pulmonary excretion may influence the results. The test is not available in the US.

\title{
Management (Figure 6)
}

\author{
- Pancreatic enzyme replacement therapy (PERT). EPI is managed with \\ exogenous PERT (Table 9). Dosing is based on the number of lipase units \\ administered per meal. For children who cannot swallow capsules, delayed \\ release capsules containing enteric coated microspheres or microtablets may be \\ opened and the contents sprinkled on soft food with low $\mathrm{pH}$ (applesauce, \\ gelatins, pureed apricot, banana or sweet potatoes). Foods with a pH greater than \\ 7.3 (milk, custard or ice cream) should be avoided as a vehicle for the sprinkled \\ enzymes because the protective enteric coating can dissolve in these foods, \\ leaving the enzymes vulnerable to inactivation by gastric acid. Pancrealipase \\ tablets or capsules should not be crushed or chewed. Concurrent administration \\ with $\mathrm{H}_{2}$ antagonists or proton pump inhibitors may enhance enzyme efficacy. \\ Vitamin supplementation. Children with EPI are prone to fat malabsorption that \\ may lead to deficiencies of the fat-soluble vitamins A, D, E, and K. Children \\ with CF should receive supplementation of these vitamins and vitamin levels \\ should be monitored annually ${ }^{85-87}$. There are no guidelines for EPI caused by \\ other diseases.
}

\section{References}

1. Nydegger A, Heine RG, Ranuh R, et al. Changing incidence of acute pancreatitis: 10-year experience at the Royal Children's Hospital, Melbourne. J Gastroenterol Hepatol. 2007; 22:13131316. [PubMed: 17489962]

2. Corfield AP, Cooper MJ, Williamson RC. Acute pancreatitis: a lethal disease of increasing incidence. Gut. 1985; 26:724-9. [PubMed: 4018637]

3. Kandula L, Lowe ME. Etiology and outcome of acute pancreatitis in infants and toddlers. J Pediatr. 2008; 152:106-10. 110. [PubMed: 18154910]

4. Bai HX, Lowe ME, Husain SZ. What have we learned about acute pancreatitis in children? J Pediatr Gastroenterol Nutr. 2011; 52:262-70. [PubMed: 21336157] 
5. Park A, Latif SU, Shah AU, et al. Changing referral trends of acute pancreatitis in children: A 12year single-center analysis. J Pediatr Gastroenterol Nutr. 2009; 49:316-322. [PubMed: 19503003]

6. Park AJ, Latif SU, Ahmad MU, et al. A comparison of presentation and management trends in acute pancreatitis between infants/toddlers and older children. J Pediatr Gastroenterol Nutr. 2010; 51:16770. [PubMed: 20479687]

7. Lopez MJ. The changing incidence of acute pancreatitis in children: a single-institution perspective. J Pediatr. 2002; 140:622-624. [PubMed: 12032533]

8. Werlin SL, Kugathasan S, Frautschy BC. Pancreatitis in children. J Pediatr Gastroenterol Nutr. 2003; 37:591-595. [PubMed: 14581803]

9. Sanchez-Ramirez CA, Larrosa-Haro A, Flores-Martinez S, et al. Acute and recurrent pancreatitis in children: etiological factors. Acta Paediatr. 2007; 96:534-537. [PubMed: 17306005]

10. Fujishiro J, Masumoto K, Urita Y, et al. Pancreatic complications in pediatric choledochal cysts. J Pediatr Surg. 2013; 48:1897-902. [PubMed: 24074664]

11. Nitsche C, Maertin S, Scheiber J, et al. Drug-induced pancreatitis. Curr Gastroenterol Rep. 2012; 14:131-8. [PubMed: 22314811]

12. Trivedi CD, Pitchumoni CS. Drug-induced pancreatitis: an update. J Clin Gastroenterol. 2005; 39:709-716. [PubMed: 16082282]

13. Spanier BW, Tuynman HA, van der Hulst RW, et al. Acute pancreatitis and concomitant use of pancreatitis-associated drugs. Am J Gastroenterol. 2011; 106:2183-8. [PubMed: 21912439]

14. Berney T, Belli D, Bugmann P, et al. Influence of severe underlying pathology and hypovolemic shock on the development of acute pancreatitis in children. J Pediatr Surg. 1996; 31:1256-61. [PubMed: 8887096]

15. Bai HX, Ma MH, Orabi AI, et al. Novel characterization of drug-associated pancreatitis in children. J Pediatr Gastroenterol Nutr. 2011; 53:423-8. [PubMed: 21681111]

16. Lowe ME, Greer JB. Pancreatitis in children and adolescents. Curr Gastroenterol Rep. 2008; 10:128-135. [PubMed: 18462598]

17. Lowe ME. Pancreatitis in childhood. Curr Gastroenterol Rep. 2004; 6:240-246. [PubMed: 15128492]

18. Chiari H. Uber die selbstverdauung des menschlichen pankreas. Z Heilk Prague. 1896; 17:1-35.

19. Sah RP, Dudeja V, Dawra RK, et al. Cerulein-induced chronic pancreatitis does not require intraacinar activation of trypsinogen in mice. Gastroenterology. 2013; 144:1076-1085.e2. [PubMed: 23354015]

20. Szmola R, Sahin-Toth M. Pancreatitis-associated chymotrypsinogen C (CTRC) mutant elicits endoplasmic reticulum stress in pancreatic acinar cells. Gut. 2010; 59:365-372. [PubMed: 19951900]

21. Morinville VD, Husain SZ, Bai H, et al. Definitions of pediatric pancreatitis and survey of present clinical practices. J Pediatr Gastroenterol Nutr. 2012; 55:261-5. [PubMed: 22357117]

22. Lin TK, Troendle DM, Wallihan DB, et al. Specialized Imaging and Procedures in Pediatric Pancreatology: A NASPGHAN Clinical Report. J Pediatr Gastroenterol Nutr. 2016

23. Shinagare AB, Ip IK, Raja AS, et al. Use of CT and MRI in emergency department patients with acute pancreatitis. Abdom Imaging. 2015; 40:272-7. [PubMed: 25078061]

24. Nydegger A, Couper RT, Oliver MR. Childhood pancreatitis. J Gastroenterol Hepatol. 2006; 21:499-509. [PubMed: 16638090]

25. Kinney TP, Freeman ML. Recent advances and novel methods in pancreatic imaging. Minerva Gastroenterol Dietol. 2008; 54:85-95. [PubMed: 18299671]

26. Tenner S, Baillie J, DeWitt J, et al. American College of Gastroenterology guideline: management of acute pancreatitis. Am J Gastroenterol. 2013; 108:1400-15. 1416. [PubMed: 23896955]

27. Wang DB, Yu J, Fulcher AS, et al. Pancreatitis in patients with pancreas divisum: imaging features at MRI and MRCP. World J Gastroenterol. 2013; 19:4907-16. [PubMed: 23946595]

28. Hallal AH, Amortegui JD, Jeroukhimov IM, et al. Magnetic resonance cholangiopancreatography accurately detects common bile duct stones in resolving gallstone pancreatitis. J Am Coll Surg. 2005; 200:869-875. [PubMed: 15922197] 
29. Banks PA, Bollen TL, Dervenis C, et al. Classification of acute pancreatitis-2012: revision of the Atlanta classification and definitions by international consensus. Gut. 2013; 62:102-11. [PubMed: 23100216]

30. Kristidis P, Bozon D, Corey M, et al. Genetic determination of exocrine pancreatic function in cystic fibrosis. Am J Hum Genet. 1992; 50:1178-1184. [PubMed: 1376016]

31. Szabo FK, Hornung L, Oparaji JA, et al. A prognostic tool to predict severe acute pancreatitis in pediatrics. Pancreatology. 2016; 16:358-64. [PubMed: 27051062]

32. Wu BU, Hwang JQ, Gardner TH, et al. Lactated Ringer's solution reduces systemic inflammation compared with saline in patients with acute pancreatitis. Clin Gastroenterol Hepatol. 2011; 9:710 717.e1. [PubMed: 21645639]

33. Szabo FK, Fei L, Cruz LA, et al. Early Enteral Nutrition and Aggressive Fluid Resuscitation are Associated with Improved Clinical Outcomes in Acute Pancreatitis. J Pediatr. 2015; 167:397402.e1. [PubMed: 26210842]

34. Mirtallo JM, Forbes A, McClave SA, et al. International consensus guidelines for nutrition therapy in pancreatitis. JPEN J Parenter Enteral Nutr. 2012; 36:284-91. [PubMed: 22457421]

35. Thompson DR. Narcotic analgesic effects on the sphincter of Oddi: a review of the data and therapeutic implications in treating pancreatitis. Am J Gastroenterol. 2001; 96:1266-72. [PubMed: 11316181]

36. Troendle DM, Barth BA. ERCP can be safely and effectively performed by a pediatric gastroenterologist for choledocholithiasis in a pediatric facility. J Pediatr Gastroenterol Nutr. 2013; 57:655-8. [PubMed: 24048163]

37. Fishman DS, Chumpitazi BP, Raijman I, et al. Endoscopic retrograde cholangiography for pediatric choledocholithiasis: Assessing the need for endoscopic intervention. World J Gastrointest Endosc. 2016; 8:425-32. [PubMed: 27298714]

38. Jazrawi SF, Barth BA, Sreenarasimhaiah J. Efficacy of endoscopic ultrasound-guided drainage of pancreatic pseudocysts in a pediatric population. Dig Dis Sci. 2011; 56:902-8. [PubMed: 20676768]

39. Lin TK, Palermo JJ, Nathan JD, et al. Timing of Cholecystectomy in Children With Biliary Pancreatitis. J Pediatr Gastroenterol Nutr. 2016; 62:118-21. [PubMed: 26308314]

40. Gurusamy KS, Nagendran M, Davidson BR. Early versus delayed laparoscopic cholecystectomy for acute gallstone pancreatitis. Cochrane Database Syst Rev. 2013:Cd010326. [PubMed: 23996398]

41. van Baal MC, Besselink MG, Bakker OJ, et al. Timing of cholecystectomy after mild biliary pancreatitis: a systematic review. Ann Surg. 2012; 255:860-6. [PubMed: 22470079]

42. Morinville VD, Lowe ME, Ahuja M, et al. Design and Implementation of Insppire (International Study Group of Pediatric Pancreatitis: in Search for a Cure). J Pediatr Gastroenterol Nutr. 2014

43. Schwarzenberg SJ, Bellin M, Husain SZ, et al. Pediatric chronic pancreatitis is associated with genetic risk factors and substantial disease burden. J Pediatr. 2015; 166:890-6.e1. [PubMed: 25556020]

44. Kumar S, Ooi CY, Werlin S, et al. Risk Factors Associated With Pediatric Acute Recurrent and Chronic Pancreatitis: Lessons From INSPPIRE. JAMA Pediatr. 2016; 170:562-9. [PubMed: 27064572]

45. Witt H, Beer S, Rosendahl J, et al. Variants in CPA1 are strongly associated with early onset chronic pancreatitis. Nat Genet. 2013; 45:1216-20. [PubMed: 23955596]

46. Fjeld K, Weiss FU, Lasher D, et al. A recombined allele of the lipase gene CEL and its pseudogene CELP confers susceptibility to chronic pancreatitis. Nat Genet. 2015

47. Ragvin A, Fjeld K, Weiss FU, et al. The number of tandem repeats in the carboxyl-ester lipase (CEL) gene as a risk factor in alcoholic and idiopathic chronic pancreatitis. Pancreatology. 2013; 13:29-32. [PubMed: 23395566]

48. Ting J, Wilson L, Schwarzenberg SJ, et al. Direct Costs of Acute Recurrent and Chronic Pancreatitis in Children in the INSPPIRE Registry. J Pediatr Gastroenterol Nutr. 2016; 62:443-9. [PubMed: 26704866]

49. Howes N, Lerch MM, Greenhalf W, et al. Clinical and genetic characteristics of hereditary pancreatitis in Europe. Clin Gastroenterol Hepatol. 2004; 2:252-261. [PubMed: 15017610] 
50. Gariepy CE, Heyman MB, Lowe ME, et al. The Causal Evaluation of Acute Recurrent and Chronic Pancreatitis in Children: Consensus From the INSPPIRE Group. J Pediatr Gastroenterol Nutr. 2016

51. Hansen TM, Nilsson M, Gram M, et al. Morphological and functional evaluation of chronic pancreatitis with magnetic resonance imaging. World J Gastroenterol. 2013; 19:7241-6. [PubMed: 24259954]

52. Kolodziejczyk E, Jurkiewicz E, Pertkiewicz J, et al. MRCP Versus ERCP in the Evaluation of Chronic Pancreatitis in Children: Which Is the Better Choice? Pancreas. 2016; 45:1115-9. [PubMed: 27101572]

53. Manfredi R, Lucidi V, Gui B, et al. Idiopathic chronic pancreatitis in children: MR cholangiopancreatography after secretin administration. Radiology. 2002; 224:675-82. [PubMed: 12202699]

54. Catalano MF, Sahai A, Levy M, et al. EUS-based criteria for the diagnosis of chronic pancreatitis: the Rosemont classification. Gastrointest Endosc. 2009; 69:1251-1261. [PubMed: 19243769]

55. Olesen SS, Bouwense SA, Wilder-Smith OH, et al. Pregabalin reduces pain in patients with chronic pancreatitis in a randomized, controlled trial. Gastroenterology. 2011; 141:536-43. [PubMed: 21683078]

56. Troendle DM, Barth BA. Pediatric Considerations in Endoscopic Retrograde Cholangiopancreatography. Gastrointest Endosc Clin N Am. 2016; 26:119-36. [PubMed: 26616900]

57. Agarwal J, Nageshwar Reddy D, Talukdar R, et al. ERCP in the management of pancreatic diseases in children. Gastrointest Endosc. 2014; 79:271-8. [PubMed: 24060520]

58. Oracz G, Pertkiewicz J, Kierkus J, et al. Efficiency of pancreatic duct stenting therapy in children with chronic pancreatitis. Gastrointest Endosc. 2014; 80:1022-9. [PubMed: 24852105]

59. Kobayashi T, Manivel JC, Bellin MD, et al. Correlation of pancreatic histopathologic findings and islet yield in children with chronic pancreatitis undergoing total pancreatectomy and islet autotransplantation. Pancreas. 2010; 39:57-63. [PubMed: 19745778]

60. Bellin MD, Freeman ML, Schwarzenberg SJ, et al. Quality of life improves for pediatric patients after total pancreatectomy and islet autotransplant for chronic pancreatitis. Clin Gastroenterol Hepatol. 2011; 9:793-9. [PubMed: 21683160]

61. Chinnakotla S, Bellin MD, Schwarzenberg SJ, et al. Total pancreatectomy and islet autotransplantation in children for chronic pancreatitis: indication, surgical techniques, postoperative management, and long-term outcomes. Ann Surg. 2014; 260:56-64. [PubMed: 24509206]

62. Bellin MD, Carlson AM, Kobayashi T, et al. Outcome after pancreatectomy and islet autotransplantation in a pediatric population. J Pediatr Gastroenterol Nutr. 2008; 47:37-44. [PubMed: 18607267]

63. Wilson GC, Sutton JM, Salehi M, et al. Surgical outcomes after total pancreatectomy and islet cell autotransplantation in pediatric patients. Surgery. 2013; 154:777-83. discussion 783-4. [PubMed: 24074415]

64. Chinnakotla S, Radosevich DM, Dunn TB, et al. Long-term outcomes of total pancreatectomy and islet auto transplantation for hereditary/genetic pancreatitis. J Am Coll Surg. 2014; 218:530-43. [PubMed: 24655839]

65. Sutherland DE, Radosevich DM, Bellin MD, et al. Total pancreatectomy and islet autotransplantation for chronic pancreatitis. J Am Coll Surg. 2012; 214:409-24. discussion 424-6. [PubMed: 22397977]

66. Walsh RM, Saavedra JR, Lentz G, et al. Improved quality of life following total pancreatectomy and auto-islet transplantation for chronic pancreatitis. J Gastrointest Surg. 2012; 16:1469-77. [PubMed: 22673773]

67. Welsh MJ, Smith AE. Molecular mechanisms of CFTR chloride channel dysfunction in cystic fibrosis. Cell. 1993; 73:1251-1254. [PubMed: 7686820]

68. Wilschanski M, Durie PR. Patterns of GI disease in adulthood associated with mutations in the CFTR gene. Gut. 2007; 56:1153-1163. [PubMed: 17446304] 
69. De BK, Weren M, Proesmans M, et al. Pancreatitis among patients with cystic fibrosis: correlation with pancreatic status and genotype. Pediatrics. 2005; 115:e463-e469. [PubMed: 15772171]

70. Ooi CY, Dorfman R, Cipolli M, et al. Type of CFTR mutation determines risk of pancreatitis in patients with cystic fibrosis. Gastroenterology. 2011; 140:153-61. [PubMed: 20923678]

71. Myers KC, Bolyard AA, Otto B, et al. Variable clinical presentation of Shwachman-Diamond syndrome: update from the North American Shwachman-Diamond Syndrome Registry. J Pediatr. 2014; 164:866-70. [PubMed: 24388329]

72. Dall'oca C, Bondi M, Merlini M, et al. Shwachman-Diamond syndrome. Musculoskelet Surg. 2012; 96:81-8. [PubMed: 22201042]

73. Dror Y, Donadieu J, Koglmeier J, et al. Draft consensus guidelines for diagnosis and treatment of Shwachman-Diamond syndrome. Ann N Y Acad Sci. 2011; 1242:40-55. [PubMed: 22191555]

74. Ammann RW, Akovbiantz A, Largiader F, et al. Course and outcome of chronic pancreatitis. Longitudinal study of a mixed medical-surgical series of 245 patients. Gastroenterology. 1984; 86:820-8. [PubMed: 6706066]

75. Layer P, Yamamoto H, Kalthoff L, et al. The different courses of early- and late-onset idiopathic and alcoholic chronic pancreatitis. Gastroenterology. 1994; 107:1481-7. [PubMed: 7926511]

76. Raeder H, Johansson S, Holm PI, et al. Mutations in the CEL VNTR cause a syndrome of diabetes and pancreatic exocrine dysfunction. Nat Genet. 2006; 38:54-62. [PubMed: 16369531]

77. Zenker M, Mayerle J, Lerch MM, et al. Deficiency of UBR1, a ubiquitin ligase of the N-end rule pathway, causes pancreatic dysfunction, malformations and mental retardation (Johanson-Blizzard syndrome). Nat Genet. 2005; 37:1345-50. [PubMed: 16311597]

78. Atik T, Karakoyun M, Sukalo M, et al. Two novel UBR1 gene mutations in a patient with Johanson Blizzard Syndrome: A mild phenotype without mental retardation. Gene. 2015; 570:153-5. [PubMed: 26149651]

79. Ellery KM, Erdman SH. Johanson-Blizzard syndrome: expanding the phenotype of exocrine pancreatic insufficiency. Jop. 2014; 15:388-90. [PubMed: 25076350]

80. Tumino M, Meli C, Farruggia P, et al. Clinical manifestations and management of four children with Pearson syndrome. Am J Med Genet A. 2011; 155a:3063-6. [PubMed: 22012855]

81. Ketwaroo G, Brown A, Young B, et al. Defining the accuracy of secretin pancreatic function testing in patients with suspected early chronic pancreatitis. Am J Gastroenterol. 2013; 108:1360 6. [PubMed: 23711627]

82. Schibli S, Corey M, Gaskin KJ, et al. Towards the ideal quantitative pancreatic function test: analysis of test variables that influence validity. Clin Gastroenterol Hepatol. 2006; 4:90-97. [PubMed: 16431310]

83. Conwell DL, Zuccaro G Jr, Vargo JJ, et al. An endoscopic pancreatic function test with cholecystokinin-octapeptide for the diagnosis of chronic pancreatitis. Clin Gastroenterol Hepatol. 2003; 1:189-94. [PubMed: 15017490]

84. Walkowiak J, Nousia-Arvanitakis S, Agguridaki C, et al. Longitudinal follow-up of exocrine pancreatic function in pancreatic sufficient cystic fibrosis patients using the fecal elastase- 1 test. $\mathrm{J}$ Pediatr Gastroenterol Nutr. 2003; 36:474-478. [PubMed: 12658038]

85. Tangpricha V, Kelly A, Stephenson A, et al. An update on the screening, diagnosis, management, and treatment of vitamin D deficiency in individuals with cystic fibrosis: evidence-based recommendations from the Cystic Fibrosis Foundation. J Clin Endocrinol Metab. 2012; 97:108293. [PubMed: 22399505]

86. Cantin AM, White TB, Cross CE, et al. Antioxidants in cystic fibrosis. Conclusions from the CF antioxidant workshop, Bethesda, Maryland, November 11-12, 2003. Free Radic Biol Med. 2007; 42:15-31. [PubMed: 17157190]

87. Borowitz D, Baker RD, Stallings V. Consensus report on nutrition for pediatric patients with cystic fibrosis. J Pediatr Gastroenterol Nutr. 2002; 35:246-259. [PubMed: 12352509]

88. Pohl JF, Uc A. Paediatric pancreatitis. Curr Opin Gastroenterol. 2015; 31:380-6. [PubMed: 26181572] 


\section{Key Points}

- Once considered rare, pancreatic diseases, specifically acute, acute recurrent and chronic pancreatitis are increasingly recognized in children.

- $\quad$ Etiologies and risk factors of adult and pediatric pancreatitis are very different, therefore it is expected that their management, natural history and response to therapy would also be different; but studies on pediatric pancreatitis are limited.

- Genetic risk factors seem to play a role in the progression from acute recurrent to chronic pancreatitis; disease burden is high in chronic pancreatitis.

- Cystic Fibrosis is the most common cause of exocrine pancreatic insufficiency in children; chronic pancreatitis and Shwachman Diamond syndrome are $2^{\text {nd }}$ most common.

- There is an urgent need for an exocrine pancreatic function that would be simple to perform, accurate, reliable, reproducible and non-invasive. 


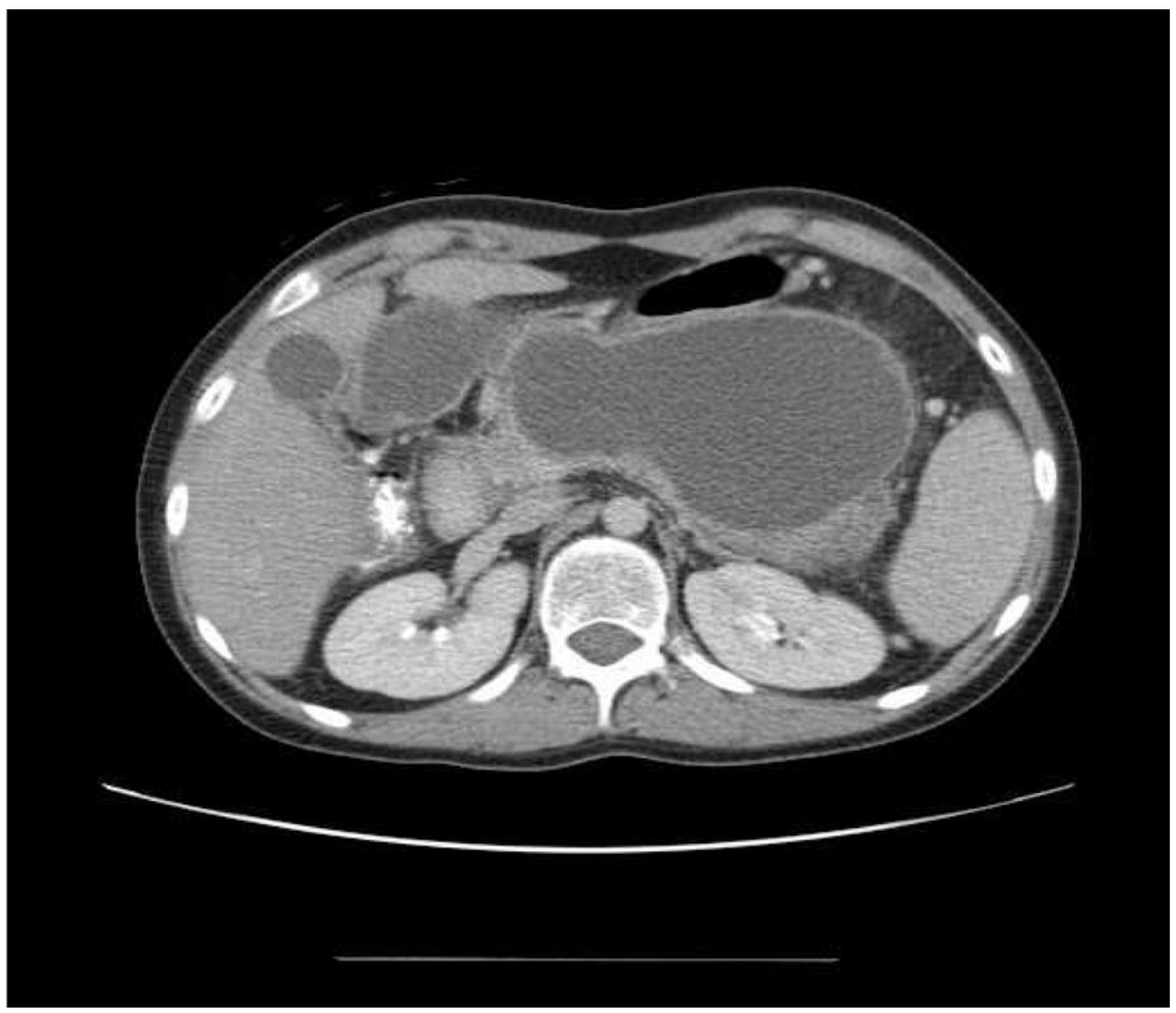

Figure 1.

CT scan showing pancreatic pseudocyst following a PEG-Asparaginase induced acute pancreatitis in a child. 


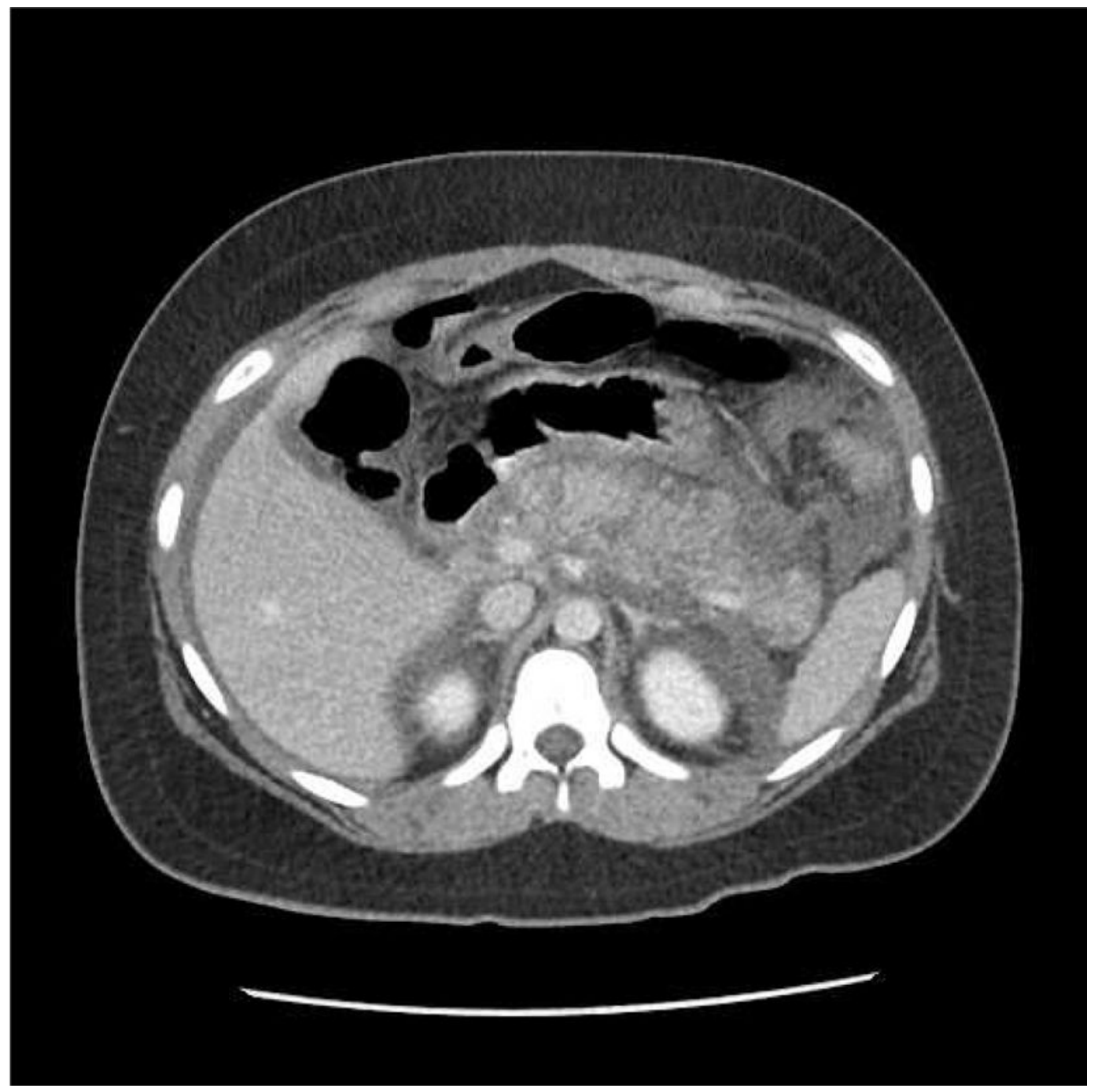

Figure 2.

CT scan in moderately severe pancreatitis in a teenager with gallstone pancreatitis.

Pancreatic and peripancreatic inflammatory changes are seen. 


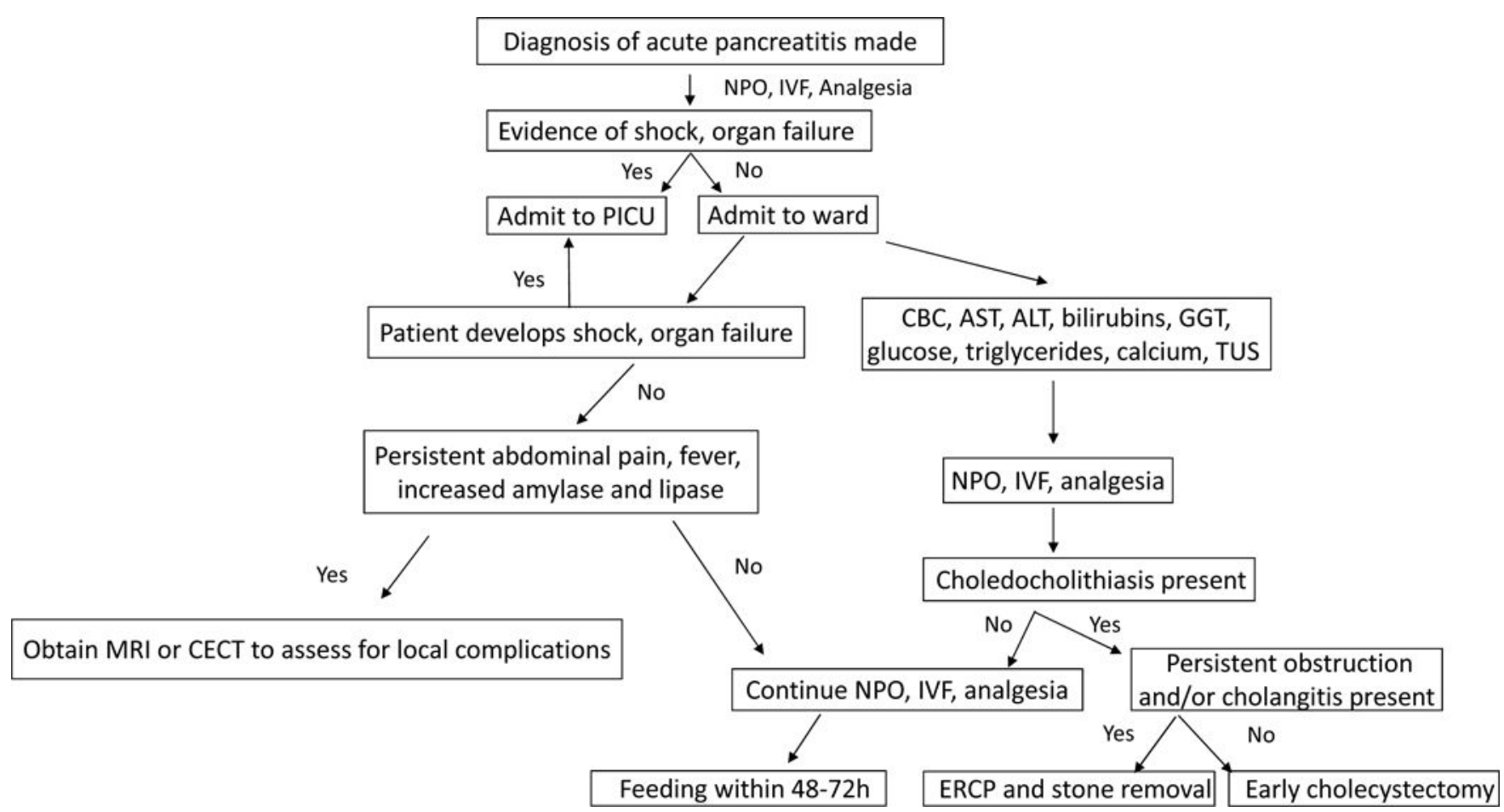

Figure 3.

Algorithm for management of acute pancreatitis and complications 


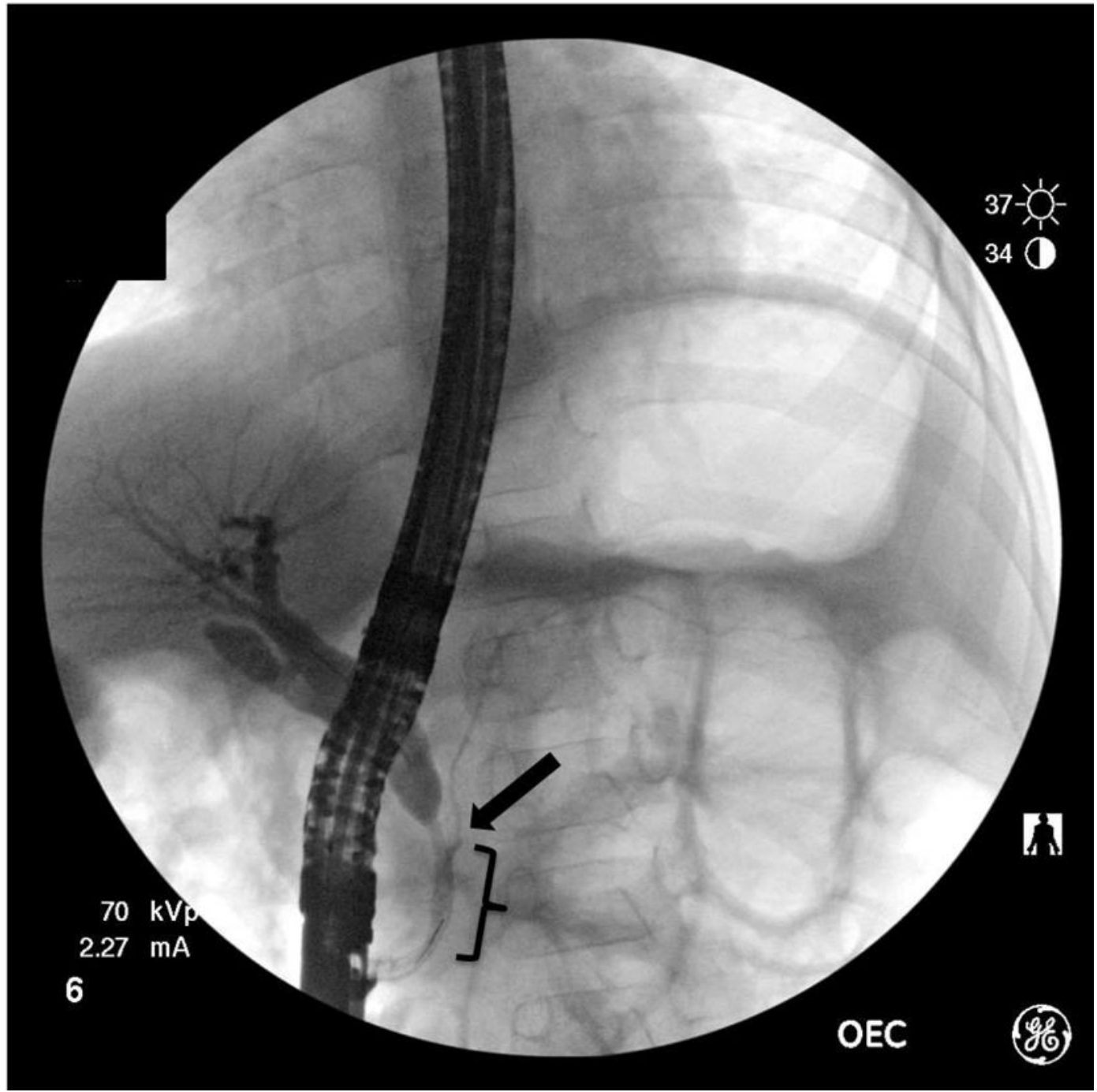

Figure 4.

ECRP study in a 5 year-old child showing anomalous biliopancreatic union. The bracket demonstrates the common channel $>1.5 \mathrm{~cm}$, and the black arrow denotes the branch point of the pancreatic duct. 


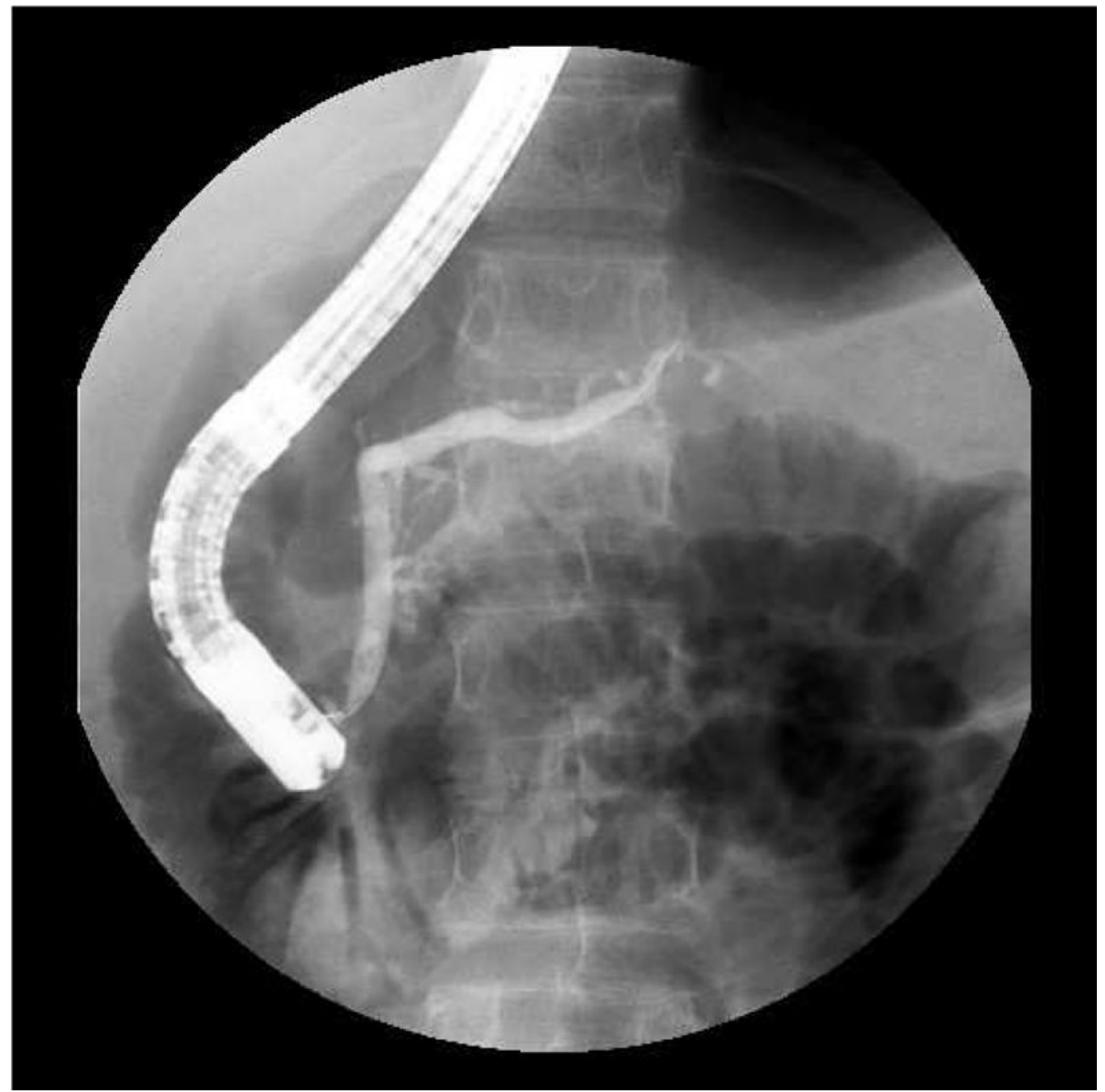

Figure 5.

ERCP study in a child showing dilated ventral pancreatic duct, along with secondary and tertiary side branch dilation. 


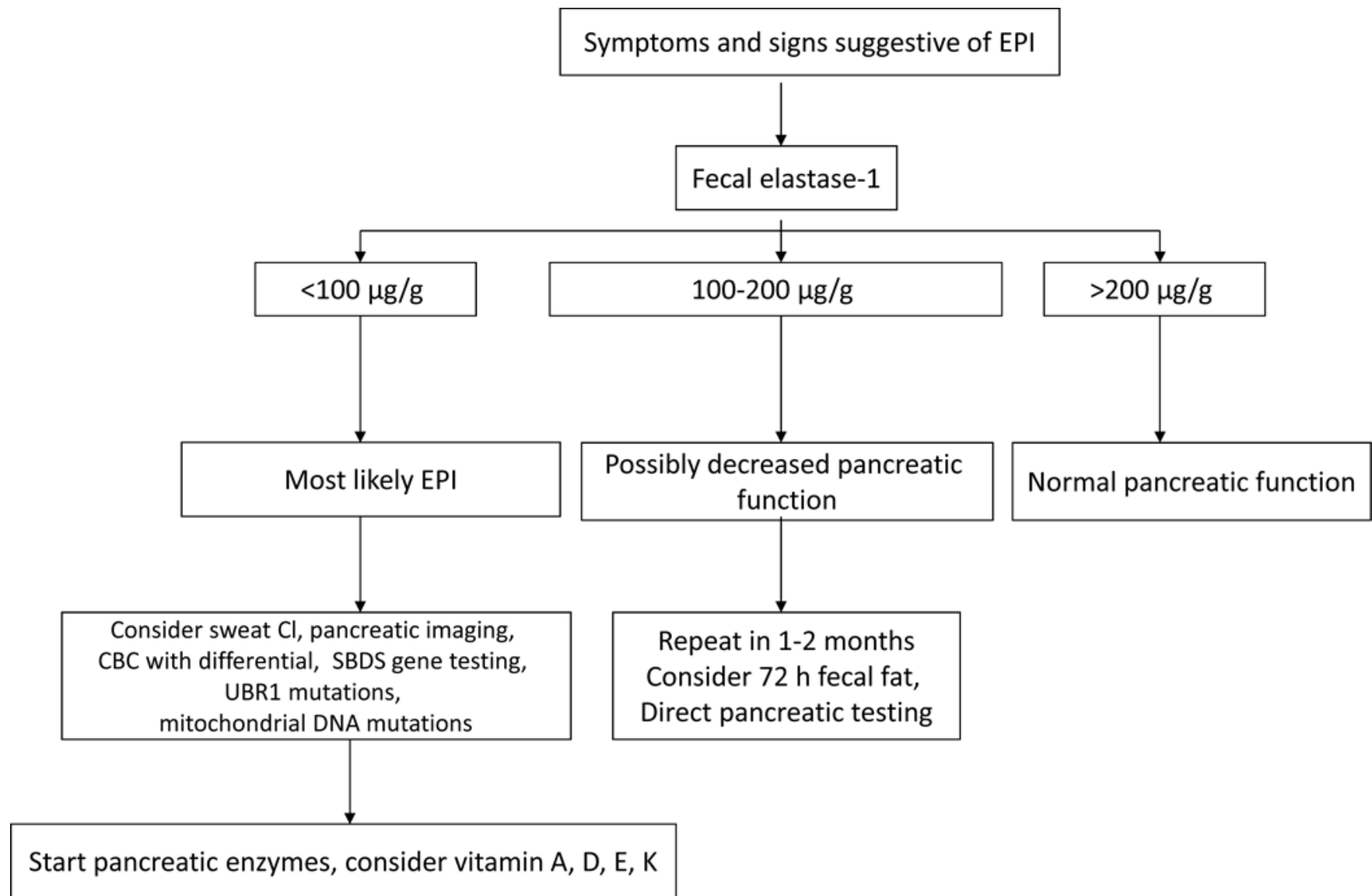

Figure 6.

Algorithm for diagnosis and management of exocrine pancreatic insufficiency 


\section{Table 1}

\section{Etiologies of Pediatric Acute Pancreatitis}

Data from refs ${ }^{3-17,88}$

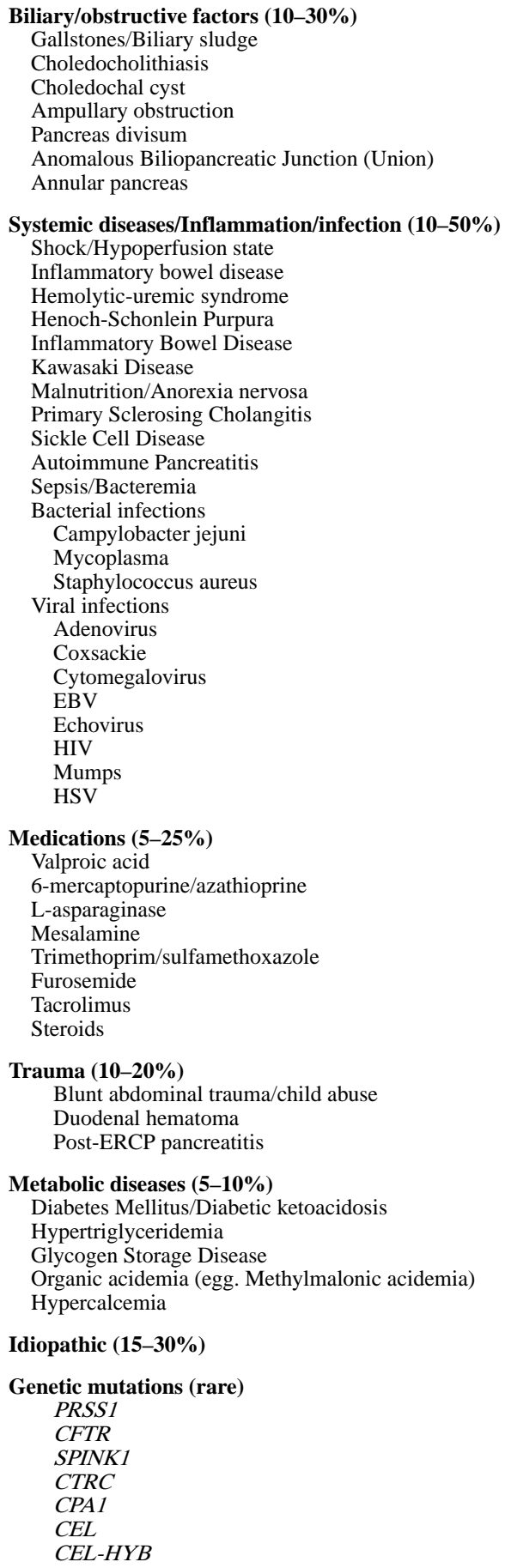


Malignancy (rare)
Lymphoma

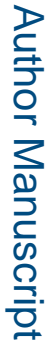

Neuroblastoma

cationic trypsinogen (PRSS1), cystic fibrosis transmembrane generator (CFTR), serine protease inhibitor Kazal type I (SPINK1), chymotrypsin-C (CTRC), carboxypeptidase 1 (CPA1), carboxylesterlipase (CEL), CEL-Hybrid (CEL-HYB) 
Table 2

Definitions of Pancreatitis in Children (INSPPIRE Criteria)

From Morinville VD, Husain SZ, Bai H, et al. Definitions of pediatric pancreatitis and survey of present clinical practices. J Pediatr Gastroenterol Nutr 2012;55:261-5.

\begin{tabular}{|c|c|}
\hline & Clinical Definition \\
\hline Acute Pancreatitis (AP) & $\begin{array}{l}\text { Requires at least } 2 \text { out of } 3 \text { criteria: } \\
\begin{array}{cl}\mathbf{1} & \text { abdominal pain suggestive of, or compatible with AP } \\
\mathbf{2} & \text { serum amylase and /or lipase activity at least } 3 \text { times greater than the upper limit of normal } \\
\mathbf{3} & \text { Imaging findings characteristic of, or compatible with AP }\end{array}\end{array}$ \\
\hline $\begin{array}{l}\text { Acute Recurrent Pancreatitis } \\
\text { (ARP) }\end{array}$ & $\begin{array}{l}\text { Requires at least } 2 \text { distinct episodes of AP, plus: } \\
\text { OR } \quad \text { Complete resolution of pain ( } \geq 1 \text { month pain-free interval between the diagnoses of AP). } \\
\text { - Complete normalization of amylase and lipase in between episodes. }\end{array}$ \\
\hline Chronic Pancreatitis (CP) & $\begin{array}{cl}\text { Requires at least } 1 \text { of the following } 3: \\
\mathbf{1} & \begin{array}{l}\text { Abdominal pain consistent with pancreatic origin and imaging findings suggestive of chronic } \\
\text { pancreatic damage- }\end{array} \\
\mathbf{2} & \text { Evidence of exocrine pancreatic insufficiency and suggestive pancreatic imaging findings } \\
\mathbf{3} & \text { Evidence of endocrine pancreatic insufficiency and suggestive pancreatic imaging findings }\end{array}$ \\
\hline
\end{tabular}

- Ductal changes: irregular contour of the main pancreatic duct or its radicles; intraductal filling defects; calculi, stricture or dilation;

- Parenchymal changes: generalized or focal enlargement, irregular contour (accentuated lobular architecture), cavities, calcifications, heterogeneous echotexture 
Table 3

Morphological Classification of Acute Pancreatitis

\begin{tabular}{|c|c|c|c|c|}
\hline Morphologic Type & \multicolumn{2}{|c|}{ Definition } & \multicolumn{2}{|c|}{ Contrast Enhanced CT findings } \\
\hline $\begin{array}{l}\text { Interstitial Edematous } \\
\text { Pancreatitis (IEP) }\end{array}$ & \multicolumn{2}{|c|}{$\begin{array}{l}\text { Acute inflammation of the pancreatic } \\
\text { parencyhma and peripancreatic tissues without } \\
\text { recognizable tissue necrosis }\end{array}$} & - & $\begin{array}{l}\text { Pancreatic parenchyma enhanced by } \\
\text { intravenous contrast } \\
\text { No peripancreatic necrosis }\end{array}$ \\
\hline Necrotizing Pancreatitis & \multicolumn{2}{|c|}{$\begin{array}{l}\text { Inflammation associated with pancreatic } \\
\text { parenchymal necrosis and/or peripancreatic } \\
\text { necrosis }\end{array}$} & • & $\begin{array}{l}\text { Pancreatic parenchyma NOT enhanced } \\
\text { by intravenous contrast and/or } \\
\text { Presence of peripancreatic necrosis } \\
\text { (ANC and WON) }\end{array}$ \\
\hline $\begin{array}{l}\text { Acute Peripancreatic Fluid } \\
\text { Collection (APFC) }\end{array}$ & & $\begin{array}{l}\text { Peripancreatic fluid associated } \\
\text { with interstitial edematous } \\
\text { pancreatitis with no associated } \\
\text { peripancreatic necrosis. } \\
\text { Only applies to fluid seen within } \\
\text { the first } 4 \text { weeks and without } \\
\text { features of a pseudocyst }\end{array}$ & • & $\begin{array}{l}\text { Occurs in the setting of IEP } \\
\text { Homogenous collection with fluid } \\
\text { density, no non-liquid component } \\
\text { Confined by normal peripancreatic } \\
\text { fascial planes } \\
\text { No definable wall encapsulating the } \\
\text { collection } \\
\text { Adjacent to pancreas (without } \\
\text { intrapancreatic extension) }\end{array}$ \\
\hline Pancreatic pseudocyst (Figure) & & $\begin{array}{l}\text { An encapsulated collection of } \\
\text { fluid with a well-defined } \\
\text { inflammatory wall } \\
\text { Usually outside the pancreas with } \\
\text { minimal or no necrosis. }\end{array}$ & $\begin{array}{l}\bullet \\
\bullet \\
\text { - } \\
\text { - } \\
\text { - }\end{array}$ & $\begin{array}{l}\text { Occurs after IEP } \\
\text { Homogenous fluid density } \\
\text { No non-liquid component } \\
\text { Well defined wall (completely } \\
\text { encapsulated) } \\
\text { Usually >4 weeks after onset of AP }\end{array}$ \\
\hline Acute Necrotic Collection & • & $\begin{array}{l}\text { Collection containing variable } \\
\text { amounts of both fluid and necrotic } \\
\text { material } \\
\text { Associated with necrotizing } \\
\text { pancreatitis } \\
\text { Involves pancreatic parenchyma or } \\
\text { peripancreatic tissues } \\
\text { Rare in children }\end{array}$ & - & $\begin{array}{l}\text { Occurs only with acute necrotizing } \\
\text { pancreatitis } \\
\text { Heterogeneous and non-liquid density } \\
\text { of varying degrees in different } \\
\text { locations } \\
\text { No definable wall encapsulating the } \\
\text { collection } \\
\text { Intrapancreatic and/or extrapancreatic }\end{array}$ \\
\hline Walled-Off Necrosis (WON) & - & $\begin{array}{l}\text { Mature encapsulated collection of } \\
\text { pancreatic and/or peripancreatic } \\
\text { necrosis } \\
\text { Usually occurs > } 4 \text { weeks after } \\
\text { onset of necrotizing pancreatitis } \\
\text { Rare in children }\end{array}$ & - & $\begin{array}{l}\text { Heterogeneous with liquid and } \\
\text { nonliquid density, varying degrees of } \\
\text { loculations } \\
\text { Well-defined wall, completely } \\
\text { encapsulated } \\
\text { Intrapancreatic and/or extrapancreatic }\end{array}$ \\
\hline
\end{tabular}

Adapted from Banks PA, Bollen TL, Dervenis C, et al. Classification of acute pancreatitis-2012: revision of the Atlanta classification and definitions by international consensus. Gut 2013;62:102-11. 


\title{
Table 4
}

\section{Grades of pancreatitis severity}

\author{
Mild acute pancreatitis \\ No organ failure \\ No local or systemic complications \\ Moderately severe acute pancreatitis \\ Organ failure that resolves within 48 hours (transient) \\ Local or systemic complications without persistent organ failure \\ Severe acute pancreatitis \\ Persistent organ failure $>48$ hours (either single or multiple organ failure)
}

Adapted from Banks PA, Bollen TL, Dervenis C, et al. Classification of acute pancreatitis-2012: revision of the Atlanta classification and definitions by international consensus. Gut 2013;62:102-11. 
Table 5

Risk factors for Pediatric Acute Recurrent and Chronic Pancreatitis

Data from Nydegger A, Couper RT, Oliver MR. Childhood pancreatitis. J Gastroenterol. Hepatol. 2006;21:499-509 and Kumar S, Ooi CY, Werlin S, et al. Risk Factors Associated With Pediatric Acute Recurrent and Chronic Pancreatitis: Lessons From INSPPIRE. JAMA Pediatr 2016;170:562-9.

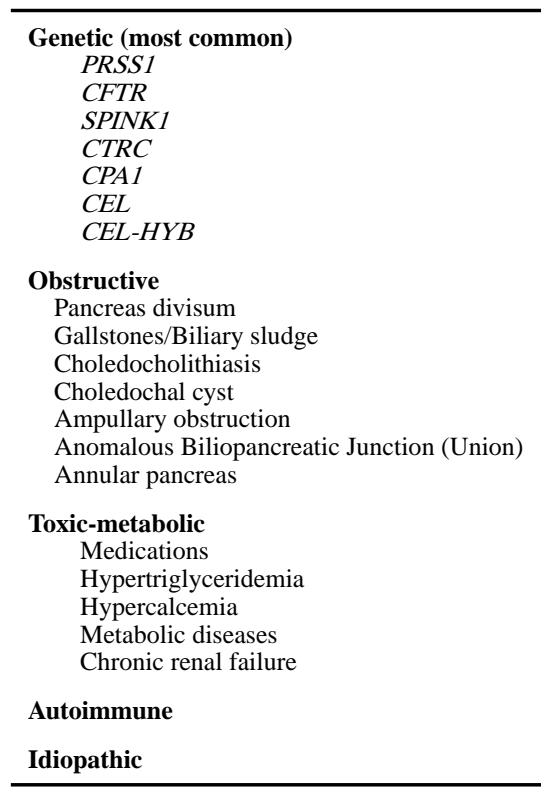

cationic trypsinogen (PRSS1), cystic fibrosis transmembrane generator (CFTR), serine protease inhibitor Kazal type I (SPINK1), chymotrypsin-C (CTRC), carboxypeptidase 1 (CPA1), carboxylesterlipase (CEL), CEL-Hybrid (CEL-HYB) 


\title{
Table 6
}

\section{Diagnostic Approach to Pediatric Acute Recurrent and Chronic Pancreatitis}

\author{
History \\ - Past and current medical history_(recurrent abdominal pain, emergency room visits, hospitalizations, medications) \\ - $\quad$ Family history of pancreatitis, pancreatic cancer, gallbladder disease \\ Biochemistry \\ - AST, ALT, GGT, total and direct bilirubin, serum triglycerides, calcium, tissue transglutaminase \\ - Consider: Stool ova and parasites, serum aminoacids and urine organic acids, esophagogastroduodenoscopy and colonoscopy in \\ select cases

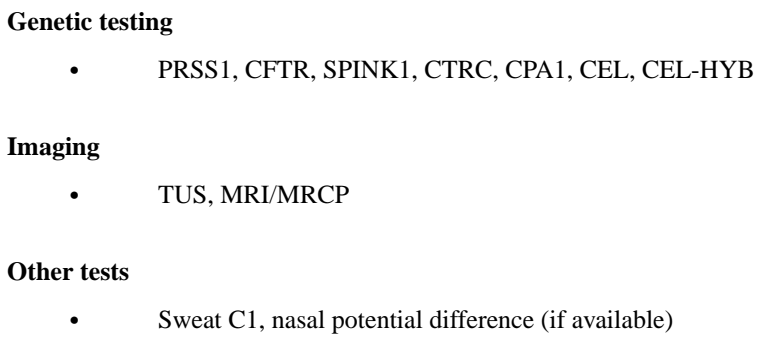

cationic trypsinogen (PRSS1), cystic fibrosis transmembrane generator (CFTR), serine protease inhibitor Kazal type I (SPINK1), chymotrypsin-C (CTRC), carboxypeptidase 1 (CPA1), carboxylesterlipase (CEL), CEL-Hybrid (CEL-HYB) 


\section{Table 7}

Etiologies of Exocrine Pancreatic Insufficiency in Childhood

Cystic fibrosis (most common)
Chronic pancreatitis
Shwachman-Diamond syndrome
Johanson-Blizzard syndrome
Pearson's syndrome
Jeune syndrome
Pancreatic aplasia
Pancreatic hypoplasia
Isolated enzyme deficiencies

Cystic fibrosis (most common)

Chronic pancreatitis

Shwachman-Diamond syndrome

Johanson-Blizzard syndrome

Pearson's syndrome

Jeune syndrome

Pancreatic aplasia

Isolated enzyme deficiencies 


\section{Table 8}

Tests for Exocrine Pancreatic Insufficiency

\begin{tabular}{cl}
\hline Direct tests & \\
- & Secretin-stimulated MRI \\
- & Dreiling tube method \\
Indirect tests & \\
- & 72h fecal fat test \\
- & Fecal elastase \\
- & ${ }^{13} \mathrm{C}$-mixed triglyceride breath test \\
\hline
\end{tabular}


Table 9

Pancreatic enzyme therapy for Exocrine Pancreatic Insufficiency

\section{Infants}

2,000 to 4,000 units per $120 \mathrm{~mL}$ of infant formula or per breast feeding

$<4$ years of age

1,000 lipase units/kg per meal and 500 lipase units/kg per snacks

$>4$ years of age.

500 lipase units/kg per meal and 250 lipase units $/ \mathrm{kg}$ per snacks 